\title{
CRITICAL FACTORS AND BENEFITS IN THE USE OF EARNED VALUE MANAGEMENT IN CONSTRUCTION
}

Joaquim Teixeira Netto

joaquimtnetto@gmail.com

Nylvandir Liberato Fernandes de Oliveira

liberato.finan@gmail.com

Andrey Pimentel Aleluia Freitas

andrey.pimentel@globo.com

João Alberto Neves dos Santos joaoalbertoneves@gmail.com

\section{ABSTRACT}

Goal: The main objective of this study is to analyze the benefits and the critical success factors (CSF) to use of Earned Value Management (EVM) in the construction projects. Design / Methodology / Approach: The research methodology was quantitative approach with statistical analysis of questionnaire with 106 answered and validated using the Cronbach's alpha and Kaiser-Meyer-Olkin.

Results: The construction companies identified the benefits and CSF in the use of EVM. The observed benefits were: achieving project cost, the definition of scope and schedule, anticipating project and project communication. The observed CSF were: team training, project management maturity, top management support, the need of pre-defined procedures, and the use of appropriate software.

Limitations of the investigation: The sample of research was composed exclusively of Brazilian construction managers.

Practical implications: Monitoring construction projects using EVM for construction companies.

Originality / Value: The EVM is widely used for project management. However, there are few studies on its use in the construction industry.

Keywords: Earned Value Indicator, Critical Success Factors, Construction Performance, Project Management. 


\section{INTRODUCTION}

In complex projects it's very common delays in scheduling and financial losses (Lopes Miranda Junior et al., 2017). Construction industry projects have suffered frequent delays and cost increases (Olivieri et al., 2016). Among the several causes of such problems are complexity of the projects and the excessive fragmentation throughout the process (Besser Freitag et al., 2017). Arrotéia et al. (2014) advocate the idea of using planning in order to achieve greater integration between the agents responsible for the project and the execution of the work. Therefore, project management associated with performance measurement systems has been proposed by different authors, especially through the use of performance indicators (Cândido et al., 2016). According to De Marco and Narbaev (2013), project performance indicators are important management tools and evaluation activities, since they allow the monitoring and achievement of the goals, besides the identification of advances and improvements of quality. Therefore, the use of performance indicators in engineering projects are very important, because it makes it possible to avoid problems that may occur during the construction, allowing adjustments and corrections to be made in order to prevent deviations in the project.

The use of Earned Value Management (EVM) as an indicator of performance in the construction industry is cited by different authors. This can be confirmed by Al-Jibouri (2003) research, showing that civil construction has adopted EVM in cost control. On the other hand, research carried out by ICPMA (International Council for Project Management Advancement, 2002) in 2002 presents the great use of EVM in construction, which has shown that the EVM is, in fact, the main performance monitoring instrument used by the industry. Other authors, such as Narbaev and De Marco (2013), emphasize the importance of this indicator to manage the scope, deadline and cost in the construction industry. The Project Management Institute points out that EVM can be thought of as management with the lights on, clearly identifying where a project is and where it is going.

Lipke (2013) argue that the use of earned value is difficult and requires good management and control. Kim et al. (2003) highlight the importance of training and practice in the use of EVM. These same authors point out that the greatest difficulty for the effective use of EVM and the understanding of the methodology, due to the difficulty of understanding, besides the need to use integrated project management software. Fleming and Koppelman (2016) emphasize the importance of using appropriate methodologies and procedures to monitor the performance through earned value. This demonstrates the importance of the application of the earned value indicator in projects, but the difficulty of using it. Netto et al. (2015), proposed the completed packet percentage indicator (PPC) together with EVM, which allows the control of the completed schedule activities.

Therefore, although the authors highlighted the importance of earned value management in construction companies, it is observed that there are difficulties in using this methodology, existing showing a gap between theory and practice in EVM use. Among the issues raised, it is necessary to identify if companies can identify the benefits of using EVM, as well as what the CSF are for the users.

This research intends to identify the benefits and CSF of construction project management, through the earned value indicator. The methodology used starts with the identification of the research hypotheses from the literature review, after which a questionnaire was applied, obtaining 106 valid answers, which were analyzed through the application of the IBM SPSS Statistics 21 software, using Kaiser-Meyer-Olkin (KMO) tests, Bartlett's sphericity and Cronbach's alpha. After analyzing the results, it was observed that the main benefit identified was to reach the objectives of the cost and schedule of the project. In relation to the critical success factors, it was observed that both training and maturity in project management are required. This work is organized in sections as follows: literature review of EVM, research method, results and conclusion.

\section{EARNED VALUE INDICATOR}

The earned value indicator assesses project performance in schedule, scope, and cost. These dimensions are recognized by the Project Management Institute (PMI) as the iron triangle, the control of which is of recognized importance for project efficiency (Project Management Institute, 2017). In order to obtain the earned value indicator, it is necessary that the activities are quantified in cost and that the completion dates of each task are defined. According to Vargas (2003), the EVM technique interconnecting the cost, schedule and scope.

Narbaev and De Marco (2013) state that the main performance indicators of the EVM are the Cost Performance Indicator (CPI) and the Schedule Performance Indicator (SPI), which are obtained from three curves: Planned Value $(P V)$, Earned Value (EV) and Actual Cost (AC). The main EVM performance indicators are calculated according to the following formulas: $\mathrm{CPI}=\mathrm{EV} / \mathrm{AC}$ and $\mathrm{SPI}=\mathrm{EV} / \mathrm{PV}$.

The ANSI/EAI 748 standard defines 32 processes for obtaining EVM. These processes were later simplified 
by the PMBOK in 1996. According to Fleming and Koppelman (2016), this simplification became ease of use in different projects. The proposed simplification has the following main processes: plan all the work for the project, compose the scope (EAP), define responsible, create an integrated chart of accounts for the EAP, integrate the scope with the schedule and cost, generate a change control baseline, create a clear measurement criterion, objectively evaluate the work done, analyze the planning variations, assess the impact of forecast indicators and use EVM to manage the company's internal processes.

The CPI measure how much return there is for each value that is invested. The interpretation of this indicator is developed with the following logic:

- If the result of the relation is equal to 1 , it is a sign that the project is running as expected.

- If the result is bigger than 1 , it is assumed that there is economy.

- If the result is less than 1 , it indicates an extra expense to the initial budget.

The SPI indicator also makes it possible to understand the chronological development of the project, compared to the pre-established schedule. This is considered of great importance due to the fact that a large number of projects are carried out in a very short time, a condition that requires a more rigorous management effort in meeting these deadlines, in order to obtain maximum utilization, which justifies the adoption of SPI. Another important aspect involves the schedule performance indicator (SPI), which considers activities that are not in the critical path, since it is considered a mistake to take into account all the activities, given that many of these activities are not critical and have some time slack for their completion (Vargas 2003).

Thus, the SPI value will be obtained by applying the earned value (EV) of deliveries, in monetary value, to the planned value (PV) of deliveries, summarized by the equation: $\mathrm{EV} / \mathrm{PV}$.

Like the CPI, the SPI can be interpreted within the following logic:

- If the value is equal to 1 , the project is proceeding as planned.

- For values bove 1 , an advanced stage will be characterized.

- Results below 1 will indicate that there is a delay in execution.
In the literature, different approaches to the CSF for the implementation of the EVM indicator were verified. A survey conducted by Kim et al. (2003) with 275 PMI (Project Management Institute) respondents identified a number of critical success factors. Among them, the main critical factors identified were: the support of the company executives, training in EVM, the culture of the organization in EVM, and the maturity of the organization in project management.

Vargas (2008), in a case study carried out in three construction companies, identified the following main critical factors: training of the planning team, definition of scope, and managerial support. On the other hand, Valle and Soares (2006), through a case study in a construction company, identified the following CSF: top management support, the training of the team in earned value management, the well-defined scope into WBS (work breakdown structure), the schedule and budget in accordance with the WBS, the assignment of responsibilities to each item of the WBS, workflow and activities, schedule and cost control, reporting of the indicators, procedures for consistency analysis and lessons learned and the continuous process of learning.

Lipke (2013) argues that although the earned value indicator has been used over the past 40 years, but application is complex and requires good management practice, which involves schedule control, precise cost control and control of earned value (work done). Stratton (2006) and Solomon and Young (2007) demonstrated the need for maturity in EVM, according to the EVM3 (Earned Value Management Maturity Model) criteria. Despite the difference between the authors, both consider the maturity in indicators management to be a critical success factor for its use. The same author discusses the use of EVM in companies, through a maturity model, which was developed by him with the designation of EVM3, and considers that companies can reach up to five levels of maturity.

\section{RESEARCH METHOD}

The research was developed in six stages. Figure 1 presents the methodological sequence.

The steps of the methodological sequence of the research are described below, according to the items defined in Figure 1:

Step 1 - Literature review of EVM.

Step 2 - Identification of the gaps in the use of the EVM methodology, the critical factors with the limitations of the use of the indicator and expected benefits in its use. 
Step 3 - Formulation of the research hypotheses, definition of the variables, elaboration of the questionnaire and verification of the sources of evidence of the research.

Step 4 - Survey with 106 respondents.

Step 5 - Results, statistical analysis and discussion.

Step 6 - Final conclusion.

In the first stage of the research, a literature review was carried out on the concepts of EVM used in the construction industry, the benefits and the CSF. In the second step, the main gaps mentioned in the literature on the use of EVM were identified. In the third stage, the research hypotheses were formulated and the observable variables that would be used to prove the hypotheses were defined.
The hypotheses of the research were based on the concepts identified in the literature review, which are described in Table 1.

Table 1 defined the hypotheses of the research, which are described in the following topics:

- H1 - The purpose of this hypothesis is to verify if the use of earned value creates value for the company and if there is in the company a perception of the importance of the use of EVM analysis for the performance of the project.

- $\mathrm{H} 2$ - It is intended, with this hypothesis, to identify the critical factors for the effective use of EVM.

After constructing the hypotheses, a set of variables was defined for each hypothesis. According to Bacharach (1989), variables are observed units, while the constructs, in turn,

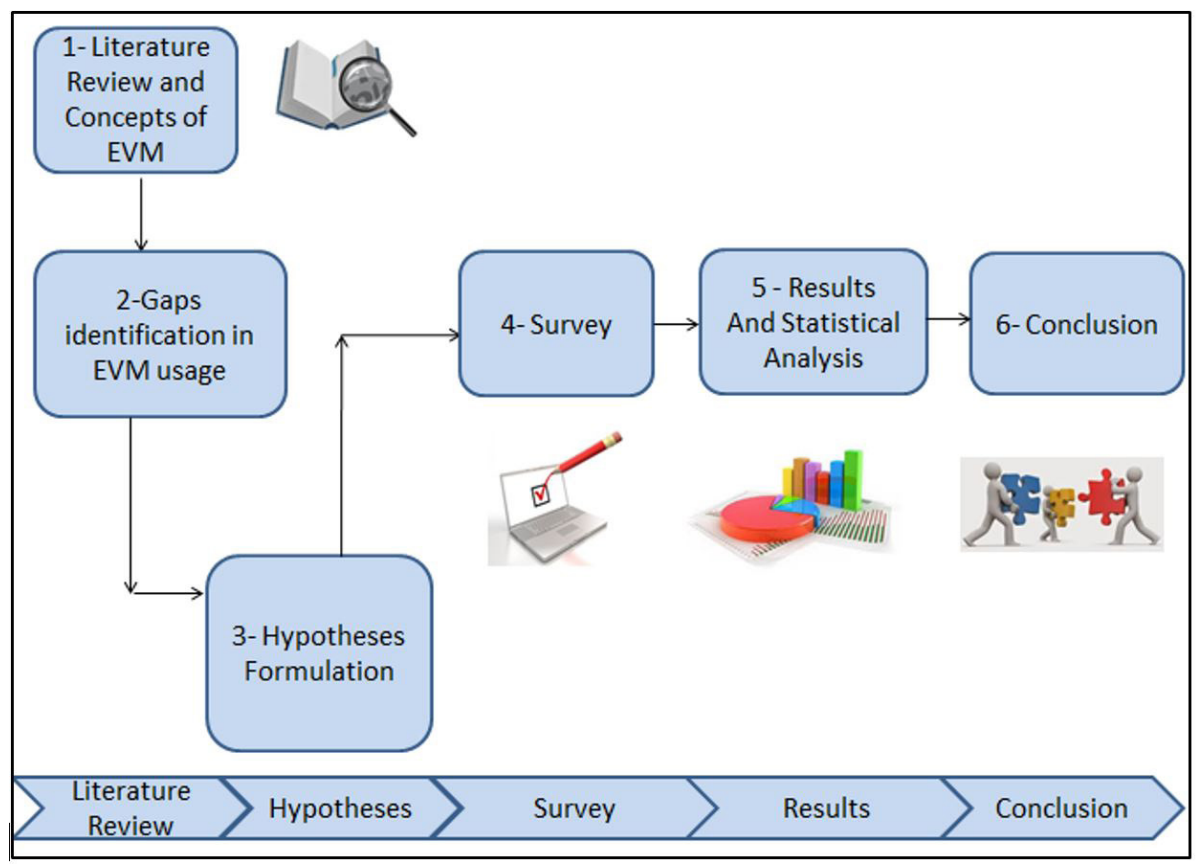

Figure 1. Research methodological sequence

Table 1. Theoretical basis of the research hypotheses

\begin{tabular}{|c|c|c|}
\hline Construct & Description & References \\
\hline $\begin{array}{c}\text { Earned value creates value } \\
\text { for the project. }\end{array}$ & $\begin{array}{c}\text { It assists in controlling the cost and scope of the project, provides } \\
\text { better communication of project performance through graphical } \\
\text { visualization of the indicators, helping the project team to achieve } \\
\text { the objectives of the schedule and costs. }\end{array}$ & Kim et al. (2003). \\
\hline H2 & $\begin{array}{c}\text { Needs top management support, EVM team training, well } \\
\text { defined scope through division into EAP items, maturity in project } \\
\text { management and maturity in EVM. }\end{array}$ & $\begin{array}{c}\text { Valle and Soares (2006), } \\
\text { and Stratton (2006). }\end{array}$ \\
\hline implementation of EVM.
\end{tabular}

Source: Authors in reference. 
Table 2. Set of constructs and variables of the research.

\begin{tabular}{|c|l|l|}
\hline \multirow{4}{*}{$\begin{array}{c}\text { Construct } \\
\text { H1 }\end{array}$} & Item & \multicolumn{1}{c|}{ Observable variables } \\
\hline \multirow{3}{*}{$\begin{array}{c}\text { EVM creates value for the } \\
\text { project. }\end{array}$} & $\mathrm{H} 1.1$ & EVM assists in defining the scope. \\
\cline { 2 - 3 } & $\mathrm{H} 1.2$ & EVM improves communication of project performance. \\
\cline { 2 - 3 } & $\mathrm{H} 1.3$ & EVM assists the project team to achieve the schedule goals. \\
\cline { 2 - 3 } & $\mathrm{H} 1.4$ & EVM assists the project team to achieve project cost objectives. \\
\cline { 2 - 3 } $\begin{array}{c}\text { H2 } \\
\text { Critical factors for the use of } \\
\text { EVM. }\end{array}$ & $\mathrm{H} 1.5$ & EVM allows project problems to be anticipated. \\
\cline { 2 - 3 } & $\mathrm{H} 2.1$ & Support from top management. \\
\cline { 2 - 3 } & $\mathrm{H} 2.2$ & Training in EVM. \\
\cline { 2 - 3 } & $\mathrm{H} 2.3$ & Maturity of the organization in projects and EVM. \\
\cline { 2 - 3 } & $\mathrm{H} 2.4$ & Use of integrated management software. \\
\cline { 2 - 3 } & $\mathrm{H} 2.5$ & Culture of the organization and senior executives. \\
\cline { 2 - 3 } & $\mathrm{H} 2.6$ & \\
\hline
\end{tabular}

Source: Adapted from Marshall (2007) and Kim et al. (2003)

are approximate units that, by their simple nature, cannot be observed directly.

In Table 2 the constructs and the search variables are defined.

In addition, a questionnaire was drawn up and validated. According to Hayes (1997, p. 57), validity refers to the degree to which the evidence supports the inferences made. That is, we can consider an instrument as valid when it measures what it proposes. Validation typically has two types: content validation and construct validation (Appelman and Sundar, 2016).

In the fifth step, the questionnaire was analyzed and checked to verify if the questions used had missing response levels lower than $10 \%$, and from this analysis, it could be guaranteed that the questionnaire had sufficient content validity. In addition, with the help of the IBM SPSS Statistics21 software, the constructs of $\mathrm{H} 1$ - EVM Assumptions Create Value for the Project and $\mathrm{H} 2$ - Critical Factors for Using EVM were checked. Cronbach's alpha estimation was also used to demonstrate how high the interrelationship between the questionnaire variables is, but, the Cronbach's alpha does not require corrections (Hayes, 1997, p. 49).

Cronbach's alpha can range from 0 to 1 , where 0 means a total lack of consistency between items, while 1 demonstrates $100 \%$ internal consistency. According to the construct validity, obtaining Cronbach's alpha values above 0.90 indicates that the variables that compose them are correlated. The Kaiser-Meyer-Olkin (KMO) and Bartlett sphericity tests were used to verify if the factorial analysis was valid for the chosen variables, and was justified by the low number of respondents in the study.

The KMO ranges from 0 to 1 . A value of 0 indicates that the sum of partial correlation is large in relation to the sum of the correlations, indicating the diffusion of the correlation pattern. Values close to 1 indicate that the correlation patterns are relatively compact and therefore the factorial analysis should generate distinct and reliable factors. Therefore, it is recommended to accept values greater than 0.5. The Bartlett sphericity test is used to examine the hypothesis that the variables are not correlated in the population. If the P-value is less than 0.05 , the hypothesis is rejected (Field, 2005, p. 6).

\section{RESULTS}

In this topic we will discuss the results according to the hypotheses defined in the methodological sequence of the research. The results were based on the response of 106 participants, using the questionnaire (in the Appendix) that was performed using IBM SPSS Statistics 21 software. It should also be noted that the questionnaire was sent by e-mail to 306 people.

The results corresponding to the $\mathrm{H} 1$ and $\mathrm{H} 2$ constructs were obtained from the same data set using the Likert scale, where 1 corresponds to Strongly Disagree and 5 corresponds to Strongly Agree. Initially, in the $\mathrm{H} 1$ construct, it was verified that less than $2 \%$ of those surveyed stopped responding to the questionnaire. Since a value of less than $10 \%$ has been obtained, it can be guaranteed that the construct has content validity. Table 3 shows the Cronbach's alpha reliability statistics.

In order to evaluate the validity of the $\mathrm{H} 1$ construct, the reliability of the data was initially calculated based on the relationship of the variables that compose it. The calculated reliability was 0.911 , higher than 0.80 , which guarantees the adequate relationship between the variables that make up the construct. Table 4 shows the KMO (Kaiser-Meyer-Olkin) test data. 
After assuring the reliability of the questionnaire, the factorial analysis was carried out. The KMO test result was 0.887 , showing that the application of the factorial analysis is valid for the chosen variables, since it generates distinct and reliable factors. The Bartlett sphericity test had a P-value of less than 0.00 , showing that the variables are correlated with the population. In this way, the application of the factor analysis fits the data. The total data variance was then verified by the principal component analysis extraction method and is summarized in Table 5 .
From the data of the variables that compose the construct, a single factor was verified whose eigen value of 3.695 is superior to 1.00 . Table 6 summarizes the load analysis of matrix $\mathrm{H} 1$.

The loading matrix was extracted with only one component and the solution cannot be rotated. The load factors were found to be greater than 0.50 , which allows it to be concluded that the data is reliable and valid. Once the data of the research is validated, the next step was analyze the results in Table 7.

Table 3. Reliability statistics - Cronbach's alpha of H1

\begin{tabular}{|c|c|c|}
\hline Cronbach's alpha & $\mathbf{N}$ & Number of items \\
\hline 0.911 & 0.911 & 5 \\
\hline
\end{tabular}

Source: SPSS Data Result

Table 4. KMO and Bartlett test

\begin{tabular}{|c|c|}
\hline KMO and Bartlett test & Values \\
\hline Kaiser-Meyer-Olkin measure & 0.887 \\
\hline Approximate chi-squared Bartlett sphericity test & 332.561 \\
\hline Df & 10 \\
\hline Sig & 0.000 \\
\hline
\end{tabular}

Source: SPSS Data Result

Table 5. Total data difference

\begin{tabular}{|c|c|c|c|c|c|c|}
\hline \multirow{2}{*}{ Component } & \multicolumn{3}{|c|}{ Initial own values } & \multicolumn{3}{c|}{ Square load extraction summations } \\
\cline { 2 - 7 } & Total & \% of variance & \% cumulative & Total & \% of variance & \% cumulative \\
\hline 1 & 3.695 & 73.905 & 73.905 & 3.695 & 73.905 & 73.905 \\
\hline 2 & 0.462 & 9.233 & 83.138 & & & \\
\hline 3 & 0.337 & 6.747 & 89.884 & & & \\
\hline 4 & 0.274 & 5.476 & 95.360 & & & \\
\hline 5 & 0.232 & 4.640 & 100.000 & & & \\
\hline
\end{tabular}

Source: SPSS Data Result

Table 6. Matrix loading

\begin{tabular}{|c|c|}
\hline VAR & Components \\
\hline VAR10 & 0.812 \\
\hline VAR12 & 0.850 \\
\hline VAR11 & 0.863 \\
\hline VAR13 & 0.870 \\
\hline VAR09 & 0.901 \\
\hline
\end{tabular}

Source: SPSS Data Result

Table 7. Search results

\begin{tabular}{|c|l|c|c|}
\hline Question & \multicolumn{1}{|c|}{ Derivative variable } & Average & Deviation \\
\hline 10 & EVM assists in defining the scope. & 3.75 & 3.58 \\
\hline 12 & EVM improves communication of project performance. & 3.75 & 1.08 \\
\hline 11 & EVM assists the project team to achieve the schedule goals. & 3.78 & 1.07 \\
\hline 13 & EVM assists the project team to achieve project cost objectives. & 3.66 & 1.07 \\
\hline 9 & EVM allows project problems to be anticipated. & 1.12 \\
\hline
\end{tabular}


The $\mathrm{H} 1$ hypotheses try to identify if the EVM creates value for the project, in different aspects that make up each question. The questionnaire for this response was based on the Likert scale, where 1 represents disagreement and 5 full agreement. The main factors are the project cost objectives with an average of 3.78 , followed by the definition of scope and schedule with 3.75 and the objective of anticipating project objectives with 3.66 and communicating the project with 3.58 .

Regarding the $\mathrm{H} 2$ construct, it was verified that none of the respondents stopped responding to the questionnaire, so we can guarantee that the construct has content validity. Table 8 summarizes the reliability data of the Cronbach's alpha of the $\mathrm{H} 2$ hypothesis.

In order to evaluate the validity of the $\mathrm{H} 2$ construct, the reliability of the data was initially calculated and resulted in a value of 0.921 , there is, there is an adequate interrelation between the variables that make up the construct, because the value is bigger then 0.8. Table 9 shows the $\mathrm{H} 2 \mathrm{KMO}$ test data.
The KMO test result was 0.891 , demonstrating the adequacy of the factorial analysis application. In Bartlett's sphericity test, the P-value is less than 0.00 , demonstrating that these variables are also correlated with the population. Therefore, the factor analysis is appropriate to the data. The analysis of the total variance of the data is summarized in Table 10.

It was verified with the data of the variables that compose the construct that there is only a single factor whose eigen value (3.802) exceeds 1.00 . Table 11 shows the loading of the $\mathrm{H} 2$ matrix.

The load factors of each variable of Construct $\mathrm{H} 2$ were also all higher than 0.50 , which allows the conclusion that the data are reliable and valid. The matrix was extracted with only one component and the solution cannot be rotated. The results of the Construct $\mathrm{H} 2$ variables are summarized in Table 12.

The $\mathrm{H} 2$ hypothesis identified the critical factors for the use of EVM in companies. The most important factors for the use of EVM by the companies were the training (question 15)

Table 8. Reliability statistics - Cronbach's alpha

\begin{tabular}{|c|c|c|}
\hline Cronbach's alpha & $\mathbf{N}$ & Number of items \\
\hline 0.921 & 0.921 & 5 \\
\hline
\end{tabular}

Source: SPSS Data Result.

Table 9. KMO and Bartlett test

\begin{tabular}{|c|c|}
\hline KMO and Bartlett test & Values \\
\hline Kaiser-Meyer-Olkin measure & 0.891 \\
\hline Bartlett sphericity test Chi-square approx. & 376.186 \\
\hline Df & 10 \\
\hline Sig & 0.000 \\
\hline
\end{tabular}

Source: SPSS Data Result.

Table 10. Total data variance

\begin{tabular}{|c|c|c|c|c|c|c|}
\hline \multirow{2}{*}{ Components } & \multicolumn{3}{|c|}{ Initial own values } & \multicolumn{3}{c|}{ Square load extraction sum } \\
\cline { 2 - 7 } & Total & \% of variance & \% cumulative & Total & \%of variance & \% cumulative \\
\hline 1 & 3.802 & 76.044 & 76.044 & 3.802 & 76.044 & 76.044 \\
\hline 2 & 0.420 & 8.410 & 84.453 & & & \\
\hline 3 & 0.316 & 6.324 & 90.777 & & & \\
\hline 4 & 0.283 & 5.664 & 96.441 & & & \\
\hline 5 & 0.178 & 3.559 & 100.000 & & & \\
\hline
\end{tabular}

Source: SPSS Data Result

Table 11. Loading matrix

\begin{tabular}{|c|c|}
\hline VAR & Components \\
\hline VAR14 & 0.846 \\
\hline VAR15 & 0.875 \\
\hline VAR16 & 0.906 \\
\hline VAR18 & 0.907 \\
\hline VAR17 & 0.823 \\
\hline
\end{tabular}


Table 12. Research results

\begin{tabular}{|c|c|l|c|c|}
\hline Construct & Question & \multicolumn{1}{|c|}{ Derivative variable } & Average & \multicolumn{1}{c|}{ Deviation } \\
\hline \multirow{4}{*}{$\begin{array}{c}\text { H2 } \\
\text { Critical factors for } \\
\text { the use of EVM. }\end{array}$} & 14 & Support from top management. & 3.95 & 1.08 \\
\cline { 2 - 5 } & 15 & Training in EVM. & 4.01 & 1.1 \\
\cline { 2 - 5 } & 16 & Maturity of the organization in projects and EVM. & 3.79 & 1.08 \\
\cline { 2 - 5 } & 17 & Use of integrated management software. & 4.0 & 1.05 \\
\hline
\end{tabular}

Source: SPSS Data Result

with an average of 4.01, followed by the maturity of the organization in projects and EVM (4.0), organizational culture of senior executives (4.0), support from top management (3.95) and use of integrated management software (3.79).

This article identified the benefits and CSF for the management of construction projects, through the EVM indicator. The advantages of using EVM (Hypothesis H1) and the CSF (Hypothesis $\mathrm{H} 2$ ) were investigated. The results as described and the results were validated and which hypothesis were independent results. The final analysis is in the next section.

\section{CONCLUSION}

The research was performed through a quantitative survey and the data were statistically analyzed by the IBM SPSS 21 software. The data were validated from the analysis of Cronbach's alpha, KMO and P-factor, and the hypotheses raised were considered true.

The main benefits observed were: achieving project cost objectives (average of 3.78), followed by the definition of scope and schedule (average of 3.75), anticipating project objectives (average of 3.66) and project communication (average of 3.58). A concordance was observed regarding the advantages of the use of EVM, confirming this hypothesis as true; that is, companies identify advantages in the use of EVM.

Regarding the CSF, the following factors can be observed in order of decreasing importance: the need of training (average of 4.01), followed by the maturity of the organization in projects and EVM (average of 4.0), organizational culture of senior executives (average of 4.0), support of senior management (average of 3.95) and use of integrated management software (average of 3.79).

The following CSF for the use of EVM were observed: team training, project management maturity, top management support, the need for pre-defined procedures, and the use of appropriate software which can integrate the cost and schedule of the project. It was also observed that the EVM provided benefits such as greater control of the cost and scope of the project, as well as providing better communication of performance, assisting the project team and achieving the objectives of the schedule and costs.

Therefore, the main contribution of this research was to identify that companies recognize that the earned value management methodology is important in the management and planning of works. However, its use is not simple and must be preceded by factors that can guarantee its successful use. The sample of research was composed exclusively of Brazilian construction managers. Therefore, research including other countries is, encouraged.

\section{REFERENCES}

Al-Jibouri, S.H. (2003), "Monitoring systems and their effectiveness for project cost control in construction", International Journal of Project Management, Vol. 21, No. 2, pp. 145-54.

Appelman, A. and Sundar, S.S. (2016), "Measuring message credibility: Construction and validation of an exclusive scale", Journalism \& Mass Communication Quarterly, Vol. 93, No. 1, pp. 59-79.

Arrotéia, A.V., Amaral, T.G. and Melhado, S.B. (2014), "Gestão de projetos e sua interface com o canteiro de obras sob a ótica da Preparação da Execução de Obras (PEO)", Ambiente Construído, Vol. 14, No. 4, pp. 183-200.

Bacharach, S.B. (1989), “Organizational Theories: some criteria for evaluation", Academy of Management Review, Vol. 14, No. 4, pp. 406-515.

Besser Freitag, A.E., Anholon, R., Oliveira, V.M. et al. (2017), "Integration of concepts about lean construction, sustainability and life cycle of buildings: a literature review", Brazilian Journal of Operations \& Production Management, Vol. 14, No. 4, pp. 486-99.

Cândido, L.F., Lima, S.H.O. and Barros Neto, J.P. (2016), "Análise de sistemas de medição de desempenho na indústria da construção", Ambiente Construído, Vol. 16, No. 2, pp. 189-208. 
De Marco, A. and Narbaev, T. (2013), “Earned value based performance monitoring of facility construction projects", Journal of Facilities Management, Vol. 11, No. 1, pp. 69-80.

Field, A. (2005). Factor Analysis using SPSS, 2nd ed., Sage, London.

Fleming, Q.W. and Koppelman, J.M. (2016), Earned value project management, Project Management Institute, Newton Square.

Hayes, B.E. (1997), Measuring customer satisfaction: Survey design, use, and statistical analysis methods, ASQ Quality Press, Milwaukee.

International Council for Project Management Advancement (2002), Response to Standards Australia on: Draft Standard for Project Performance Measurement Using Earned Value V5.6. IPCMA.

Kim, E., Wells Junior, W.G. and Duffey, M.R. (2003), "A model for effective implementation of Earned Value Management methodology", International Journal of Project Management, Vol. 21, No. 5, pp. 375-82.

Lipke, W. (2013), "Is something missing from project management", Crosstalk, Vol. 26, No. 4, pp. 16-20.

Lopes Miranda Junior, H., Bezerra, N.R.A., Bezerra, M.J.S. et al. (2017), "The internet of things sensors technologies and their applications for complex engineering projects: A digital construction site framework", Brazilian Journal of Operations \& Production Management, Vol. 14, No. 4, pp. 567-76.

Marshall, R.A. (2007), "The contribution of earned value management to project success on contracted efforts", Journal of Contract Management, Vol. 5, No. 1, pp. 21-33.
Narbaev, T. and De Marco, A. (2013), "Combination of growth model and earned schedule to forecast project cost at completion", Journal of Construction Engineering and Management, Vol. 140, No. 1, pp. 1-10.

Netto, J., Quelhas, O., Moreira, L. et al. (2015). “Proposta de indicadores de valor agregado e PPC (Percentual de Pacotes Concluídos) em obras: estudo de caso", in Congresso Nacional de Excelência em Gestão, pp. 1-20.

Olivieri, H., Granja, A.D. and Picchi, F.A. (2016), "Planejamento tradicional, Location-Based Management System e Last Planner System: um modelo integrado", Ambiente Construído, Vol. 16, No. 1, pp. 265-83.

Project Management Institute (2017), Guia de Gerenciamento de Projetos PMBOK, 5th ed., PMI, Newtown Square, PA.

Solomon, P.J. and Young, R.R. (2007), Performance-based earned value. J. Wiley \& Sons, New York.

Stratton, R.W. (2006), The earned value management maturity model. Management Concepts Inc., Tysons Corner.

Valle, J.A. and Soares, C.A.P. (2006), "The use of Earned Value Analysis (EVA) in the cost management of construction projects", in Proceedings of the project management institute global congress, Project Management Institute, Newtown Square, PA, pp. 1-11.

Vargas, R.V. (2003), "Earned value analysis in the control of projects: Success or failure", AACE International Transactions, Vol. 21, No. 4, pp. 211-4.

Vargas, R. (2008), Análise de valor agregado em projetos, 3rd ed., Brasport, Rio de Janeiro, RJ.

Received: 01 Oct 2018

Approved: 27 May 2019

How to cite: Netto, J.T., Oliveira, N.L.F. and Freitas, A.P.A. et al. (2020),“Critical factors and benefits in the use of earned value management in construction", Brazilian Journal of Operations \& Production Management, Vol. 17, No. 1, e2020571. https://doi.org/10.14488/ BJOPM.2020.007 
Appendix. Questionnaire used in the research

\begin{tabular}{|c|c|}
\hline Item & Description \\
\hline 1 & What is the branch of your company? \\
\hline 2 & What is your area of activity in the projects? \\
\hline 3 & What is your role in the company? \\
\hline 4 & What is the region of your work? \\
\hline 5 & What is the size of your company? \\
\hline 6 & In a typical project, what is the role of your company? \\
\hline 7 & What is your experience in project management (in years)? \\
\hline 8 & Which answer best fits the project management in your company? \\
\hline 9 & $\begin{array}{l}\text { Rate from } 1 \text { (disagree) to } 5 \text { (fully agree) the following statement: EVM allows for predicting possible problems in the project in } \\
\text { advance. }\end{array}$ \\
\hline 10 & Rate from 1 (disagree) to 5 (fully agree) the following statement: EVM improves scope control. \\
\hline 11 & Rate from 1 (disagree) to 5 (fully agree) the following statement: EVM assists the project team in meeting schedule goals. \\
\hline 12 & Rate from 1 (disagree) to 5 (fully agree) the following statement: EVM improves project communication \\
\hline 13 & $\begin{array}{l}\text { Rate from } 1 \text { (disagree) to } 5 \text { (fully agree) the following statement: EVM assists the project team in meeting project cost } \\
\text { objectives. }\end{array}$ \\
\hline 14 & Rate from 1 (disagree) to 5 (fully agree) regarding the importance to EVM's success: Top management support. \\
\hline 15 & Rate from 1 (disagree) to 5 (fully agree) regarding the importance to the success of EVM: EVM Training. \\
\hline 16 & Rate from 1 (disagree) to 5 (fully agree) regarding the importance to EVM's success: Maturity of the organization in projects. \\
\hline 17 & $\begin{array}{l}\text { Rate from } 1 \text { (disagree) to } 5 \text { (fully agree) regarding the importance to the success of EVM: Organization culture and senior } \\
\text { executives. }\end{array}$ \\
\hline 18 & Rate from 1 (disagree) to 5 (fully agree) regarding the importance to EVM's success: Use of appropriate software. \\
\hline
\end{tabular}

